\title{
Association between the Length of Interpregnancy Interval and Pregnancy Outcomes in Women with One Previous Caeserian Section Undergoing a Repeat Caeserian Delivery at Term at Pumwani Maternity Hospital between 2014 and 2018 a Cross-Sectional Study
}

\author{
Auma Adipo*, Diana Ondieki, Omondi Ogutu, Anne Pulei \\ The University of Nairobi, Nairobi, Republic of Kenya \\ Email: *adipo555@gmail.com
}

How to cite this paper: Adipo, A., Ondieki, D., Ogutu, O. and Pulei, A. (2021) Association between the Length of Interpregnancy Interval and Pregnancy Outcomes in Women with One Previous Caeserian Section Undergoing a Repeat Caeserian Delivery at Term at Pumwani Maternity Hospital between 2014 and 2018 a Cross- Sectional Study. Open Journal of Obstetrics and Gynecology, 11, 80-87.

https://doi.org/10.4236/ojog.2021.112010

Received: January 9, 2021

Accepted: February 6, 2021

Published: February 9, 2021

Copyright () 2021 by author(s) and Scientific Research Publishing Inc. This work is licensed under the Creative Commons Attribution International License (CC BY 4.0).

http://creativecommons.org/licenses/by/4.0/ (c) (i) Open Access

\begin{abstract}
Caesarean sections constitute major surgery, and are associated with immediate maternal and perinatal risks with implications on future pregnancies. After a caesarean delivery, the World Health Organization (WHO) recommends an Inter-pregnancy Interval (IPI) of at least 24 months to lower the risk of adverse maternal and perinatal outcomes in the subsequent pregnancy. However, whether the recommendation confers obstetric benefits is unclear as there's paucity of data in low- and medium-income countries (LMIC). The objective was to determine the association between IPI length and maternal and neonatal outcomes in women with one previous caesarian section undergoing a repeat caesarian delivery at term in Pumwani Maternity Hospital between $1^{\text {st }}$ January 2014 and $31^{\text {st }}$ December 2018. A cross-sectional study was done where patients who had delivered via repeat caesarean section at term between $1^{\text {st }}$ January 2014 and $31^{\text {st }}$ December 2018 were evaluated. The files of 625 patients were retrieved and IPI was determined from the time interval between a previous caesarean section delivery and the beginning of the subsequent pregnancy, established from the date of the last normal menstrual period as recorded or extrapolated from an early trimester obstetric scan. The files were allotted to study groups as follows: $<24$ months/short IPI $(\mathrm{n}=170)$, 24 - 29 months/intermediate IPI $(\mathrm{n}=384)$, and $60+$ months/long IPI $(\mathrm{n}=$ 121) and data on sociodemographic/reproductive characteristics and mater-
\end{abstract}


nal and neonatal outcomes abstracted and uploaded to SPSS (version 21) worksheet. Descriptive, bivariate, and multivariate logistic regression analyses were done and a p-value of 0.05 was considered statistically significant. The demographic and reproductive characteristics were comparable across the three IPI groups. Maternal outcomes such as uterine rupture, post-partum haemorrhage (PPH), blood transfusions, preeclampsia, and maternal mortality were comparable across short, intermediate, and long IPI. Some neonatal outcomes, however, showed evidence of an association with IPI. These were prematurity $(\mathrm{p}=0.03)$ and developing congenital malformations $(\mathrm{p}=0.01)$. Other neonatal outcomes (birth outcomes, birth weight, Apgar at 5, and NBU admission) were similar. In conclusion, maternal outcomes are comparable when the IPI after a repeat caesarean section at term is short, intermediate, and long. Congenital anomalies and premature births should be anticipated when the IPI is long (more than 59 months).

\section{Keywords}

Interpregnancy interval, Caesarean Sections, Pumwani Maternity Hospital

\section{Introduction}

The WHO recommends the interval between a woman's previous caesarian delivery and her subsequent pregnancy be a minimum of 24 months [1]. Long and short IPIs increase health risks for both the mother and neonate. A study in the USA observed that both short and long IPIs are associated with adverse maternal and neonatal outcomes [2], with a short IPI linked with greater risks of experiencing fetal growth restriction, preterm birth, low birth weight, and perinatal, infant and child mortality [3]. Studies have also associated long IPI with maternal outcomes such as pre-eclampsia and sub-fertility in women after a previous caesarian pregnancy [4]. However, according to a WHO technical report on birth spacing [5], there is a need for evidence from Africa, as most available data emanate from the developed world.

\section{Materials and Methods}

A cross sectional study design was employed to determine the association between short, intermediate, and long interpregnancy intervals and maternal and neonatal outcomes among women undergoing a repeat caesarean delivery after one previous caesarean section between 1st January 2014 to 31st December 2018 at the Pumwani Maternity Hospital (PMH). PMH is the largest and oldest maternity hospital in Kenya recording over 24,000 deliveries yearly. It is located four kilometres east of Nairobi central business district. The patients seen here are often of low-income earners from Nairobi and Kiambu County booked for vaginal or CS births.

The inclusion criteria included women with one previous CS birth who had a 
repeat caesarean delivery at term at PMH between January 2014 and December 2018. Women with multi-foetal gestation and uncontrolled medical conditions in pregnancy were excluded from the study.

Cochran's 1977 statistical formula for cross-sectional studies was used to calculate sample size $(\mathrm{N})$ for the study group. Individual sample sizes were calculated to ensure that short, intermediate, and long IPI groups were adequately represented using these parameters: prevalence $(\mathrm{p})$ of pre-term birth (one of the predominant neonatal outcomes) in IPI $<24$ months was $12.57 \%, 24$ - 59 months (18.56\%) and $\geq 60$ months (10.16\%) from a study by Mahande et al. in 2016 [6], standard normal variate $(\mathrm{Z})(1.96)$, and absolute error (d) of 5\%. Therefore, 163 women with a short IPI, 233 with an intermediate IPI, and 148 with a short IPI were required for this study. To recruit participants' files, simple random sampling was used. The file numbers in each study group were coded from 1-n, the numbers uploaded into QuickCalcs random number generator at (https://www.graphpad.com/quickcalcs) and study files selected randomly.

Trained records officers retrieved the archived files of women who delivered at Pumwani Hospital from 2014-2018 via a repeat CS after one previous CS delivery and their IPIs ascertained. Files were grouped according to their IPIs $(<24$ months, 24 - 59 months, and $\geq 60$ months). The sheet had three main sections. The first section recorded the socio-demographic characteristics, including parity and outcome of their previous deliveries. Part two of the data abstraction sheet recorded the maternal outcomes after the repeat CS, including development of PPH, need for blood transfusion and hospital stay among others. Ultrasound reports and the LNMP dates were used to calculate gestation period. Part three recorded neonatal outcomes including the APGAR scores, birth weight, need for NBU admission among other outcomes.

Data analysis was done using Statistical Package for Social Scientists (SPSS) version 21 software. Data was entered and cleaned. Shapiro Wilke Test was first used to determine the distribution of data. The means of continuous data were calculated, categorical data summarized as frequencies and percentages, and the Chi square test and logistic regression used for comparative statistical analyses. A p-value $<0.05$ was considered to be significant.

Kenyatta National Hospital/University of Nairobi and Pumwani Hospital ethical approvals were obtained. Personal information of the participants was kept confidential and no personal identifying information such as names and identification numbers were recorded. There was no direct risk to participants since data was extracted from hospital records.

\section{The Results}

A review of 17,410 files yielded 1269 patients who delivered through CS after a previous CS birth. The files of 1269 were screened for eligibility and those with more than one previous CS $(n=464)$, comorbidities in pregnancy $(n=18)$, and incomplete data [>20\%] $(n=112)$ were excluded $(n=594)$. In total, 675 were 
recruited, 170 (25.2\%) with a short IPI (<24 months), 384 (56.9\%) an intermediate IPI (24 - 59 months), and 121 (17.8) a long IPI (>59 months), and their demographic, medical, and obstetrics data reviewed as shown in Figure 1.

In the comparative analysis of the demographic and obstetric characteristics of women with short, intermediate and long IPI (Table 1), only parity, outcome of previous caesarean section and gestation at first ANC were found to be significant $(P<0.01)$. This was only seen when short and intermediate IPI were compared, and when short and long IPI were compared. This was not seen when intermediate and long IPI were compared. No evidence of association was found when marital status, caesarean section, and ANC attendance were compared among the three IPI groups.

In Table 2, on analysis of maternal outcomes, uterine ruptures were lower among participants with a short and long IPI compared to intermediate IPI, however this was not statistically significant. $\mathrm{PPH}$ was lower among participants with short IPI compared to intermediate IPI, and higher among participants with a short IPI compared to a long IPI but this was not statistically significant. Incidence of $\mathrm{PPH}$, need for blood transfusion, preeclampsia and maternal mortality were comparable among the three IPI groups.

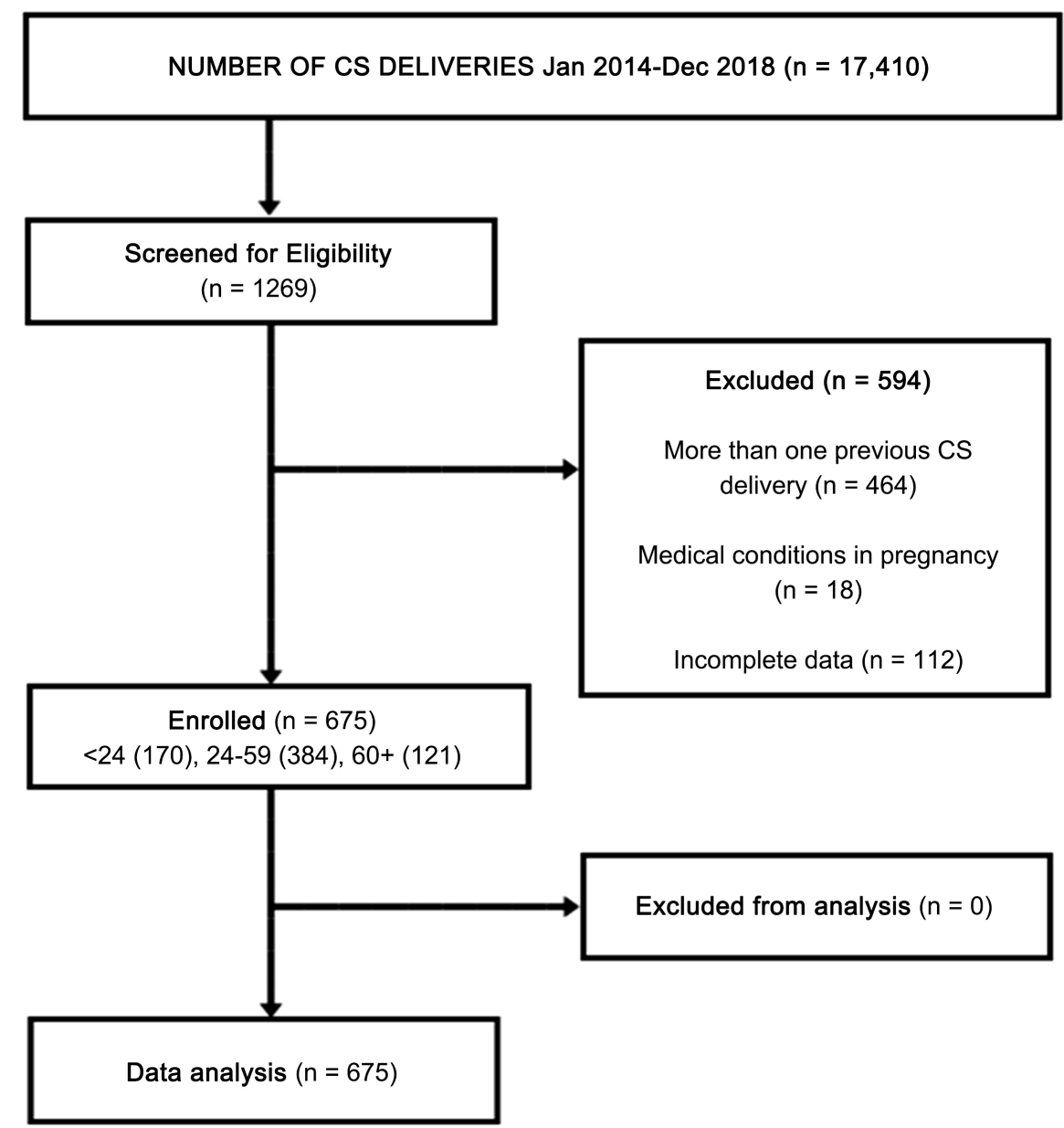

Figure 1. Recruitment procedure for study participants. 
When it came to neonatal outcomes (Table 3), patients with a short IPI compared to intermediate IPI were less likely to deliver babies with low birth weight $(\mathrm{P}=0.03)$ and babies with congenital anomalies $(\mathrm{P}=0.01)$. In addition, participants with an intermediate IPI compared to a long IPI were less likely to deliver babies with congenital anomalies $(\mathrm{P}=0.03)$ and premature babies $(\mathrm{P}=0.03)$. The birth weight of babies, birth outcomes, Apgar score at 5, need for NBU admission, RDS and macrosomia occurred in a similar pattern among the three IPI groups.

Table 1. Demographic and obstetrics characteristics of women with short, intermediate, and long interpregnancy interval after one previous caesarean section.

\begin{tabular}{|c|c|c|c|c|c|c|c|}
\hline & & \multicolumn{3}{|c|}{ Interpregnancy Interval (Months) } & \multicolumn{3}{|c|}{$P$ value } \\
\hline & & $\begin{array}{c}<24(\mathrm{~S}) \\
(\mathrm{n}=170)\end{array}$ & $\begin{array}{c}24-59(\mathrm{I}) \\
(\mathrm{n}=384)\end{array}$ & $\begin{array}{c}60+(\mathrm{L}) \\
(\mathrm{n}=121)\end{array}$ & S/I & $\mathrm{S} / \mathrm{L}$ & $\mathrm{I} / \mathrm{L}$ \\
\hline \multirow{3}{*}{ Age } & $<19$ & $3(1.8)$ & $2(0.5)$ & $0(0.0)$ & Ref & Ref & Ref \\
\hline & $19-34$ & $151(88.8)$ & $362(94.3)$ & $103(85.1)$ & 0.15 & 0.27 & 1.00 \\
\hline & $>34$ & $16(9.4)$ & $20(5.2)$ & $18(14.9)$ & 0.64 & 0.22 & 0.49 \\
\hline \multirow{3}{*}{ Marital } & Married & $160(94.70)$ & $362(94.3)$ & $114(94.2)$ & 0.86 & 0.86 & 0.98 \\
\hline & Single & $9(5.3)$ & $22(5.7)$ & $7(5.8)$ & Ref & Ref & Ref \\
\hline & Missing & 1 & 0 & 0 & & & \\
\hline \multirow{5}{*}{ Education } & None & $7(4.1)$ & $11(2.9)$ & $3(2.5)$ & Ref & Ref & Ref \\
\hline & Primary & $65(38.5)$ & $250(65.1)$ & $65(53.7)$ & 0.06 & 0.22 & 0.07 \\
\hline & Secondary & $76(45.0)$ & $116(30.2)$ & $50(41.3)$ & 0.95 & 0.54 & 0.49 \\
\hline & Tertiary & $21(12.4)$ & $7(1.8)$ & $3(2.5)$ & 0.01 & 0.22 & 0.63 \\
\hline & Unknown & 1 & 0 & 0 & & & \\
\hline \multirow{2}{*}{ Parity } & 1 to 3 & 154 (90.6) & $379(98.7)$ & $119(98.3)$ & $<0.01$ & $<0.01$ & 0.77 \\
\hline & $4+$ & $16(9.4)$ & $5(1.3)$ & $2(1.7)$ & Ref & Ref & Ref \\
\hline \multirow{3}{*}{ Prev. CS } & Live & $121(85.8)$ & & $78(96.3)$ & Ref & Ref & Ref \\
\hline & Still & $20(14.2)$ & $13(5.2)$ & $3(3.7)$ & $<0.01$ & 0.01 & 0.58 \\
\hline & Unknown & 29 & 133 & 40 & & & \\
\hline \multirow{3}{*}{ Type of CS } & Elective & $16(9.5)$ & & $11(9.1)$ & Ref & Ref & Ref \\
\hline & Emergency & $152(90.5)$ & $354(92.2)$ & $110(90.9)$ & 0.50 & 0.90 & 0.65 \\
\hline & Unknown & 2 & 0 & 0 & & & \\
\hline \multirow{3}{*}{ ANC visits } & Yes & $163(97.0)$ & $374(97.7)$ & $116(95.9)$ & 0.66 & 0.59 & 0.29 \\
\hline & No & $5(3.0)$ & $9(2.3)$ & $5(4.1)$ & Ref & Ref & Ref \\
\hline & Unknown & 2 & 1 & 0 & & & \\
\hline \multirow{3}{*}{ ANC visits } & Less than 4 & $45(28.8)$ & $68(18.2)$ & $22(19.8)$ & $<0.01$ & 0.09 & 0.70 \\
\hline & 4 or more & $111(71.2)$ & $305(81.8)$ & $89(80.2)$ & Ref & Ref & Ref \\
\hline & Missing & 14 & 11 & 10 & & & \\
\hline \multirow{3}{*}{$\begin{array}{l}\text { Gestation } \\
\text { (first ANC) }\end{array}$} & $1^{\text {st }}$ Trimester & $85(57.4)$ & $317(85.2)$ & $91(82.0)$ & Ref & Ref & Ref \\
\hline & After First & $63(42.6)$ & $55(14.8)$ & $20(18.0)$ & $<0.01$ & $<0.01$ & 0.40 \\
\hline & Unknown & 22 & 12 & 10 & & & \\
\hline
\end{tabular}

S-Short interpregnancy interval ( $<24$ months); I-Intermediate interpregnancy interval ( 24 - 59 months); L-Long interpregnancy interval ( $>59$ months); S/I-short vs intermediate IPL; S/L—short vs long IPL; S/I—short vs intermediate IPL; CS—caesarean section; ANC—Antenatal clinic; Ref-reference group. 
Table 2. Comparison of maternal outcomes of participants with a short, intermediate, and long interpregnancy interval after one caesarean section delivery.

\begin{tabular}{|c|c|c|c|c|c|c|}
\hline & \multicolumn{3}{|c|}{ Interpregnancy Interval (Months) } & \multicolumn{3}{|c|}{$P$ value } \\
\hline & $\begin{array}{c}<24(\mathrm{~S}) \\
(\mathrm{n}=170)\end{array}$ & $\begin{array}{c}24-59(\mathrm{I}) \\
(\mathrm{n}=384)\end{array}$ & $\begin{array}{c}60+(\mathrm{L}) \\
(\mathrm{n}=121)\end{array}$ & S/I & $S / L$ & $\mathrm{I} / \mathrm{L}$ \\
\hline Uterine rupture & $1(0.6)$ & $3(0.8)$ & $1(0.8)$ & 0.80 & 0.80 & 0.96 \\
\hline PPH & $6(3.5)$ & $15(3.9)$ & $3(2.5)$ & 0.83 & 0.61 & 0.46 \\
\hline Blood transfusion & $9(5.3)$ & $12(3.1)$ & $4(3.3)$ & 0.21 & 0.41 & 0.92 \\
\hline Preeclampsia & $1(0.6)$ & $2(0.5)$ & $0(0.0)$ & 0.92 & - & - \\
\hline Maternal mortality & $2(1.2)$ & $7(1.8)$ & $2(1.7)$ & 0.57 & 0.73 & 0.90 \\
\hline ALOS (days) [mean (SD)] & $4.87(2.27)$ & $4.00(0.77)$ & $4.13(1.33)$ & $<0.01$ & 0.01 & 0.18 \\
\hline
\end{tabular}

S-short interpregnancy interval ( $<24$ months); I-intermediate interpregnancy interval (24 - 59 months); L-Long interpregnancy interval ( $>59$ months); S/I—short vs intermediate IPL; S/L_short vs long IPL; S/I—short vs intermediate IPL; SD—standard deviation; PPH—Postpartum haemorrhage; ALOS— Average length of stay.

Table 3. Comparison of neonatal outcomes of participants with a short, intermediate, and long interpregnancy interval after one caesarean section delivery.

\begin{tabular}{|c|c|c|c|c|c|c|c|}
\hline & & \multicolumn{3}{|c|}{ Interpregnancy Interval (Months) } & \multicolumn{3}{|c|}{$P$ value } \\
\hline & & $\begin{array}{c}<24(\mathrm{~S}) \\
(\mathrm{n}=170)\end{array}$ & $\begin{array}{c}24-59(\mathrm{I}) \\
(\mathrm{n}=384)\end{array}$ & $\begin{array}{c}60+(\mathrm{L}) \\
(\mathrm{n}=121)\end{array}$ & S/I & $S / L$ & $\mathrm{I} / \mathrm{L}$ \\
\hline \multirow{3}{*}{ Birth outcome } & Still & $8(4.7)$ & $19(4.9)$ & $6(5.0)$ & 0.92 & $0 / 93$ & 0.99 \\
\hline & Live & $160(94.1)$ & $365(95.1)$ & $115(95.0)$ & Ref & Ref & Ref \\
\hline & EPD & $2(1.2)$ & $0(0.0)$ & $0(0.0)$ & 0.09 & 0.51 & - \\
\hline \multirow{3}{*}{ Birth weight } & $<2500$ & $22(12.9)$ & $26(6.8)$ & $12(9.9)$ & 0.12 & 0.46 & 0.24 \\
\hline & $2500-4000$ & $146(85.9)$ & $347(90.4)$ & $105(86.8)$ & Ref & Ref & Ref \\
\hline & $>4000$ & $2(1.2)$ & $11(2.9)$ & $4(3.3)$ & 0.28 & 0.22 & 0.75 \\
\hline \multirow{2}{*}{ Apgar at 5} & $<7$ & $25(14.7)$ & $43(11.2)$ & 12 99.9) & 0.24 & 0.22 & 0.69 \\
\hline & $7-10$ & $145(85.3)$ & $341(88.8)$ & $109(90.1)$ & Ref & Ref & Ref \\
\hline \multicolumn{2}{|c|}{ Congenital abnormalities } & $1(0.6)$ & $6(1.6)$ & $6(5.0)$ & 0.34 & 0.01 & 0.03 \\
\hline \multicolumn{2}{|c|}{ NBU admission } & $38(22.4)$ & $66(17.2)$ & $23(19.0)$ & 0.15 & 0.48 & 0.64 \\
\hline \multicolumn{2}{|c|}{ Asphyxia } & $24(14.1)$ & $40(10.4)$ & $9(7.4)$ & 0.20 & 0.07 & 0.33 \\
\hline \multicolumn{2}{|c|}{ RDS } & $5(2.9)$ & $8(2.1)$ & $5(4.1)$ & 0.53 & 0.58 & 0.21 \\
\hline \multicolumn{2}{|c|}{ NNS } & $1(0.6)$ & $2(0.5)$ & $0(0.0)$ & 0.92 & 1.00 & 1.00 \\
\hline \multicolumn{2}{|c|}{ Prematurity } & $8(4.7)$ & $12(3.1)$ & $9(7.4)$ & 0.35 & 0.32 & 0.03 \\
\hline \multicolumn{2}{|c|}{ Low birth weight } & $7(4.1)$ & $26(6.8)$ & $13(10.7)$ & 0.22 & 0.03 & 0.15 \\
\hline \multicolumn{2}{|c|}{ Macrosomia } & $2(1.2)$ & $12(3.1)$ & $4(3.3)$ & 0.17 & 0.38 & 0.92 \\
\hline
\end{tabular}

S-short interpregnancy interval (<24 months); I-intermediate interpregnancy interval (24 - 59 months); L-Long interpregnancy interval ( $>59$ months); S/I-short vs intermediate IPL; S/L-short vs long IPL; S/I—short vs intermediate IPL; NBU-Newborn unit; RDS—respiratory distress syndrome; NNS— Non-nutritive sucking; EDP—early preterm delivery. 


\section{Discussion}

The study was done to determine the association between short, intermediate, and long IPI and maternal and neonatal outcomes among women with one previous caesarian section undergoing a repeat caesarian delivery at term at PMH. Majority of the participants were aged between 20 - 34 years, married, and had primary level of education. Majority had live births via emergency caesarian section, and attended four or more ANC, mostly during the first trimester of pregnancy. Overall, the demographic and reproductive characteristics of women with short, intermediate, and long IPI were comparable and similar to the findings of Thoma et al. [7] in the USA. However, the findings were different from the findings of Gemmil and Lindberg that showed women with a short IPI were likely to be younger and with tertiary level of education [8].

Eleven deaths were reported over the duration of the study, seven occurred among women with intermediate IPI, two in the short IPI, and two in the long IPI group. However, these were not statistically significant when compared across IPI groups. The prevalence of adverse maternal outcomes such as PPH and preeclampsia were also similar across the three IPI groups, as opposed to the findings of Mahande and Obure in Tanzania [6] who found out that an IPI of 37 - 59 months, categorized as long, was associated with an increased risk of adverse pregnancy outcomes.

The neonatal outcomes were largely similar with the incidence of live births reported to be $94.1 \%, 95.1 \%$, and $95.0 \%$ among women with short, intermediate, and long IPI respectively. Birth weights were within the normal range while the need for NBU admission and occurrence of asphyxia and respiratory distress were minimal and similar across the IPI groups. However, the incidence of congenital anomalies was found to be higher when IPI was long versus intermediate and short. This was statistically significant. A case control study by Kwon et al. [9] found similar results in 2012, with women with an IPI $\geq 60$ months having a higher risk of delivering an infant with a birth defect than when IPI was $8-23$ months or less than six months.

The key strength of this study was that it investigated a matter of great public health importance that had not been studied in Kenya before. Globally also, few studies had evaluated the effect of IPI after a CS birth, even though IPI forms part of the WHO policy on child and maternal health.

Limitations in this study included files of some patients lacking a few important variables such as socio-economic status that could have benefited the study. Moreover, data for gestation age was generated from multiple documents, which could have introduced bias.

\section{Conclusion}

Maternal outcomes are similar across short, intermediate, and long interpregnancy intervals after a repeat caesarean section at term. However, there is a higher likelihood of developing congenital malformations, prematurity, and low 
birth weight when IPI is long after a repeat caesarian section.

\section{Acknowledgements}

Sincere appreciation to Dr. Diana Ondieki, Professor Omondi Ogutu, and Dr. Anne Pulei for their tireless efforts in supervision and guidance. Appreciation to the Pumwani Maternity Hospital.

\section{Conflicts of Interest}

The authors declare no conflicts of interest regarding the publication of this paper.

\section{References}

[1] World Health Organisation (2007) Report of a WHO Technical Consultation on Birth Spacing. World Health Organization, 34 p.

[2] Kallan, J. (1992) Effects of Interpregnancy Intervals on Preterm Birth, Intrauterine Growth Retardation, and Fetal Loss. Social Biology, 39, 231-245. https://doi.org/10.1080/19485565.1992.9988819

[3] Smith, G.C.S., Pell, J.P. and Dobbie, R. (2003) Interpregnancy Interval and Risk of Preterm Birth and Neonatal Death: Retrospective Cohort Study. The BMJ, 327, 313. https://doi.org/10.1136/bmj.327.7410.313

[4] O’Neill, S.M., Kearney, P.M., Kenny, L.C., Henriksen, T.B., Lutomski, J.E., Greene, R.A., et al. (2013) Caesarean Delivery and Subsequent Pregnancy Interval: A Systematic Review and Meta-Analysis. BMC Pregnancy Childbirth, 13, Article No. 165. http://bmcpregnancychildbirth.biomedcentral.com/articles/10.1186/1471-2393-13-1 $\underline{65}$ https://doi.org/10.1186/1471-2393-13-165

[5] WHO (2005) Report of a WHO Technical Consultation on Birth Spacing. Report of a WHO Technical Consultation on Birth Spacing, 13, 13-15.

[6] Mahande, M.J. and Obure, J. (2016) Effect of Interpregnancy Interval on Adverse Pregnancy Outcomes in Northern Tanzania: A Registry-Based Retrospective Cohort Study. BMC Pregnancy Childbirth, 16, Article No. 140.

http://bmcpregnancychildbirth.biomedcentral.com/articles/10.1186/s12884-016-092 9-5 https://doi.org/10.1186/s12884-016-0929-5

[7] Thoma, M., Copen, C. and Kirmeyer, S. (2016) Short Interpregnancy Intervals in 2014: Differences by Maternal Demographic Characteristics. National Library of Medicine National Center for Biotechnology Information, 240, 1-8.

[8] Gemmill, A. and Lindberg, L.D. (2013) Short Interpregnancy Intervals in the United States. Obstetrics \& Gynecology, 122, 64-71.

[9] Kwon, S., Lazo-Escalante, M., Villaran, M.V. and Li, C.I. (2012) Relationship between Interpregnancy Interval and Birth Defects in Washington STATE. Journal of Perinatology, 32, 45-50. https://doi.org/10.1038/jp.2011.49 